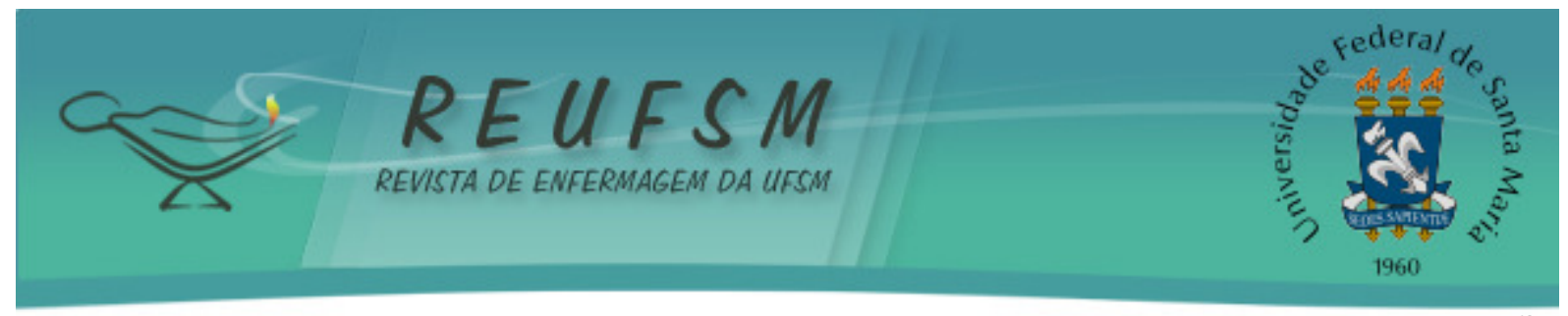

ARTIGO DE REFLEXÃO

\title{
PROFESSORES DE ENFERMAGEM E O DESENVOLVIMENTO DE COMPETÊNCIAS: REFLEXÕES SOBRE A TEORIA DE PHILIPPE PERRENOUD
}

\author{
TEACHER NURSING AND THE COMPETENCES DEVELOPMENT: REFLECTIONS ON \\ PHILIPPE PERRENOUD'S THEORY
}

\section{PROFESORES DE ENFERMERÍA Y EL DESARROLLO DE COMPETENCIAS: REFLEXIONES SOBRE LA TEORÍA DE PHILIPPE PERRENOUD}

Doi: $10.5902 / 2179769214498$

\author{
Saionara Nunes de Oliveira ${ }^{1}$ \\ Mariely Carmelina Bernardi ${ }^{2}$ \\ Marta Lenise do Prado 3 \\ Daniele Delacanal Lazzari ${ }^{4}$ \\ Murielk Motta Lino ${ }^{5}$ \\ Maria do Carmo Vicensi ${ }^{6}$
}

RESUMO: Objetivo: refletir sobre as dez competências necessárias aos docentes, propostas por Perrenoud, sob a ótica do ensino superior em enfermagem. Método: trata-se de uma reflexão teórica. Resultados: na formação do enfermeiro, a partir das Diretrizes Curriculares Nacionais instituídas há mais de uma década, aponta-se para a necessidade de desenvolver habilidades e competências das mais diversas ordens. No entanto, permanece ainda a necessidade de os professores, neste cenário, construírem saberes e fomentarem reflexão, apropriando-se das possibilidades ofertadas pela noção de competências. Conclusões: reflete-se que as dez competências apresentadas por Philippe Perrenoud oferecem possibilidades que permitem aos docentes repensarem e redirecionarem suas práticas, adequando ou ofertando novas possibilidades de ensino conforme situação ou espaço de aprendizagem.

Descritores: Ensino; Competência profissional; Educação em enfermagem; Docentes de enfermagem.

ABSTRACT: Aim: to reflect about the ten competencies necessary to the teacher, proposed by Perrenoud, from the perspective of higher education in nursing. Method: theoretical reflection. Results: in nursing education, considering the National Curriculum Guidelines established for over a decade, it is emphasized the need to develop skills and competencies in numerous orders. However, the need of teachers to build knowledge and foster reflection, appropriating themselves of possibilities offered by the notion of competence, in this scenario, remains. Conclusion: it is reflected that the ten competencies presented by Philippe Perrenoud offer possibilities that allow teachers to rethink and redirect their practices, adapting or offering new educational possibilities as situation or learning space.

Descriptors: Teaching; Professional competence; Education, nursing; Faculty, nursing.

\footnotetext{
${ }^{1}$ Enfermeira. Mestre em Enfermagem. Docente da Universidade Federal de Santa Catarina. Florianópolis, Santa Catarina, Brasil. E-mail: saionaranunes@gmail.com

${ }^{2}$ Enfermeira. Doutoranda em Enfermagem. Universidade Federal de Santa Catarina. Bolsista Pró-ensino na saúde. Florianópolis, Santa Catarina, Brasil. E-mail: marielybernardi@yahoo.com.br

${ }^{3}$ Enfermeira. Doutora em Enfermagem. Docente da Universidade Federal de Santa Catarina. Bolsista PQ/CNPq. Florianópolis, Santa Catarina, Brasil. E-mail: marta.lenise@ufsc.br

${ }^{4}$ Enfermeira. Mestre em Educação. Doutoranda em Enfermagem. Universidade Federal de Santa Catarina. Bolsista CNPq. Florianópolis, Santa Catarina, Brasil. E-mail: danielelazza@gmail.com

${ }^{5}$ Enfermeira. Mestre em Enfermagem. Enfermeira do Trabalho na Eletrosul Centrais Elétricas. Florianópolis, Santa Catarina, Brasil. E-mail: muryelk@gmail.com

${ }^{6}$ Enfermeira. Mestre em Ciências da Saúde Humana. Docente da Universidade do Oeste de Santa Catarina. Joaçaba, Santa Catarina, Brasil. Email: maria.vicensi@unoesc.edu.br
} 


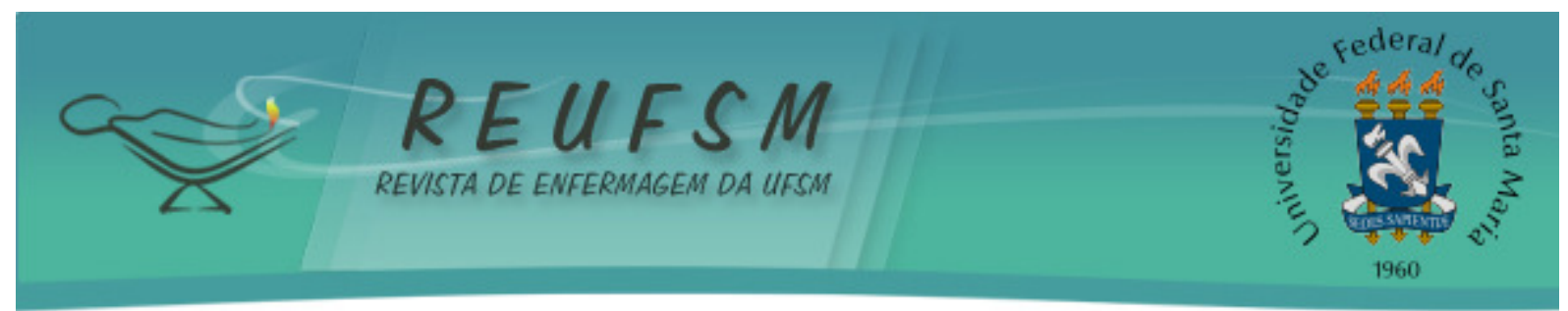

RESUMEN: Objetivo: reflexionar acerca de las diez competencias necesarias para el profesor, propuestas por Perrenoud, desde la perspectiva de la educación superior en enfermería. Método: es una reflexión teórica. Resultados: en la formación de enfermería, desde las Directrices Curriculares Nacionales establecidas hace más de una década, se apunta la necesidad de desarrollar habilidades y competencias de distintos órdenes. Todavía queda la necesidad de profesores fomentar la reflexión y el conocimiento, apropiándose de posibilidades que ofrecen el concepto de competencia. Conclusión: las diez competencias presentados por Philippe Perrenoud ofrecen posibilidades y permiten a los profesores repensar y reorientar sus prácticas, adaptándose a la oferta de nuevas oportunidades educativas de acuerdo con la situación o el espacio de aprendizaje.

Descriptores: Enseñanza; Competencia profesional; Educación en enfermería; Docentes de enfermería.

\section{INTRODUÇÃO}

O termo competência tem estado presente nas ciências da educação há décadas, englobando a produção de comportamentos em uma determinada área e demandando compreensão sobre seu significado. Desta forma, tem provocado, com considerável frequência, equívocos e controvérsias sobre seu significado, incluindo dificuldades de identificar, de modo claro, os fenômenos que este pretende objetivar. ${ }^{1}$

Em linhas gerais, a noção de competência designa a capacidade de produzir uma conduta em um determinado domínio. Por, em tempos atuais, ser um termo exageradamente utilizado, provoca numerosos conflitos. Porém, se pensada exclusivamente na lógica da formação profissional, determina certa eficiência ao desempenhar uma ação. ${ }^{2}$

Desta forma, o conceito de competência é abrangente e polissêmico, abrange a esfera do trabalho e da educação e vem sendo utilizado com a finalidade de associar o conhecimento teórico e prático, considerando o indivíduo como capaz de tal realização. Perrenoud afirma que a noção de competência não deve ser compreendida por uma ótica caricatural em que apenas os saberes do senso comum ou da experiência são mobilizados. Para este autor, competência é a capacidade de mobilizar um conjunto de recursos cognitivos (saberes, capacidades, informações, entre outros) a fim de solucionar com pertinência e eficácia uma série de situações. ${ }^{3}$

Neste contexto, para além das questões ideológicas justapostas à discussão acerca das competências, as Diretrizes Curriculares Nacionais (DCNs) para os Cursos de Graduação em Enfermagem, em vigência desde 2001, reorientaram a formação na área para o desenvolvimento de habilidades e competências das mais diversas ordens, incluindo a atenção a saúde, tomada de decisões, comunicação, liderança, administração e gerenciamento. ${ }^{4}$

Nesta lógica, permanece a necessidade de os docentes de enfermagem situarem-se neste cenário a fim de construir saberes e fomentar a reflexão sobre suas experiências ${ }^{4}$, sendo uma das responsabilidades do professor a provocação do espírito crítico, reflexivo e criativo em seus alunos. ${ }^{5}$ A competência, enquanto capacidade de agir eficazmente em um determinado tipo de situação, fomenta a prática reflexiva e esta é a base para a construção das competências. ${ }^{4-6}$

Ao discutir de que modo é possível desenvolver as competências necessárias ao ensino, Perrenoud defende uma metodologia baseada em pedagogia ativa, colaborativa e partilhada, com o aluno participando ativamente da construção do conhecimento. ${ }^{4}$ Para isso, propôs o desenvolvimento e compreensão de dez grandes famílias de competências: 1) organizar e dirigir situações de aprendizagem; 2) administrar a progressão das aprendizagens; 3 ) conceber e fazer com que os dispositivos de diferenciação evoluam; 4) envolver os alunos em suas aprendizagens e em seu trabalho; 5) trabalhar em equipe; 6) participar da administração da escola; 7) informar e envolver os pais; 8) utilizar novas 


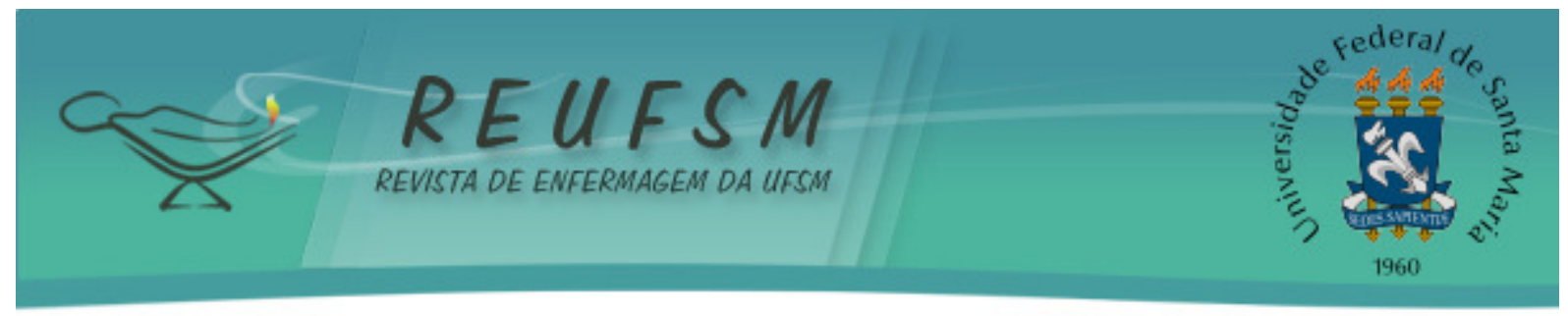

tecnologias; 9) enfrentar os deveres e os dilemas éticos da profissão; 10) administrar a

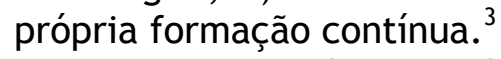

Assim, o objetivo desta reflexão teórica é refletir sobre as dez competências necessárias aos docentes, propostas por Perrenoud, sob a ótica do ensino superior em enfermagem.

\section{As dez competências para ensinar}

Perrenoud discute seus conceitos com o enfoque na educação infantil, porém, suas ideias são amplamente aplicáveis em qualquer campo da educação. Dessa forma, as competências serão aqui apresentadas e discutidas, adaptadas ao contexto da educação em enfermagem, mais especificamente com foco no desenvolvimento de competências pelo enfermeiro docente.

\section{Organizar e dirigir situações de aprendizagem}

0 desenvolvimento desta competência favorece no docente a reflexão e a clareza sobre o que ele faz e quais são suas intenções ao propor determinada situação de ensino, incluindo para tanto, o domínio do conteúdo e a sua transposição didática. ${ }^{7}$

Elaborar e incentivar a criação de projetos de pesquisa, por exemplo, é também um dos elementos chaves das situações de aprendizagem, pois desenvolve a capacidade de identificar e resolver problemas, de engajar os alunos na busca de soluções possíveis para qualquer situação. É também um caminho eficiente para a descoberta de si mesmo e do outro, concebendo a integralidade como ação social, primando pela não objetivação do sujeito e favorecendo relações dialógicas. ${ }^{7-9}$

\section{Administrar a progressão das aprendizagens}

Essa competência requer a disposição do professor para observar, acompanhar e gerenciar o conhecimento ao longo do processo formativo. Visa o movimento rumo à pedagogia diferenciada e à individualização dos percursos de formação, realizando periodicamente um balanço de competências e tomando decisões de maneira progressiva. ${ }^{7}$

Professores que valorizam o seu fazer e cuidam do seu próprio processo de aquisição de conhecimentos, renovando-os permanentemente, evidenciam uma competência capaz de repensar as práticas do cuidado humano. Dessa forma, promovem o aprendizado evidenciando a responsabilidade permanente dos enfermeiros com a produção do conhecimento. ${ }^{10}$

\section{Conceber e fazer evoluir os dispositivos de diferenciação}

Esse aspecto envolve considerar a heterogeneidade dos alunos, desenvolver a cooperação entre eles, planejar atividades diferenciadas conforme os tipos e níveis de aprendizagem, fornecer apoio e ampliar a gestão de classe. ${ }^{7}$

Seria preciso romper com o paradigma ditatorial de aulas, provas e critérios de avaliação iguais para alunos diferentes, com dificuldades e experiências distintas e então, criar situações de aprendizagem diferenciadas, permitindo vivências significativas. Isso possibilita que cada aluno também tenha condições de perceber quais os meios de aprendizagem que mais lhe permitem crescer. $^{9}$

Os desafios desta competência situam-se na ordem das práticas profundamente enraizadas no cotidiano escolar, que priorizam a homogeneidade como o mais importante elemento constitutivo da totalidade. Nesta ótica, há tendência de secundarizar as 


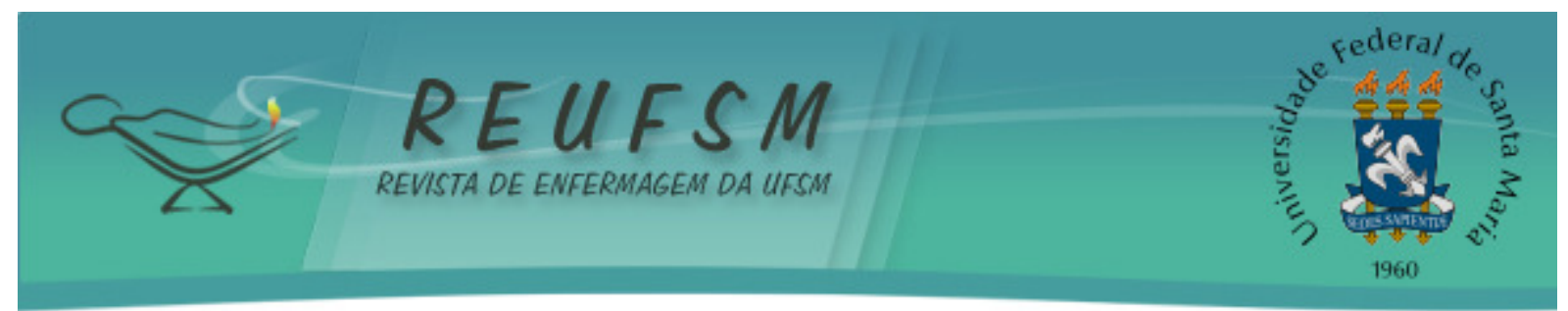

inúmeras diferenças culturais e de aprendizado possíveis, consideradas, por vezes, como um problema a resolver. ${ }^{11-12}$

\section{Envolver os alunos em suas aprendizagens e em seu trabalho}

Esta competência discute a necessidade do professor desenvolver estratégias para promover uma educação que faça sentido aos alunos. ${ }^{3}$ Ao envolver os alunos na condução das atividades, este deixa de ser somente um agente passivo que recebe e cumpre ordens. ${ }^{7}$ A partir do desenvolvimento desta competência, o docente dá sentido da atividade pedagógica e sua relação com o saber.

\section{Trabalhar em equipe}

As atividades em equipe permitem ao professor trabalhar de forma multidisciplinar, elaborar projetos em equipes com os alunos, professores, gestores escolares, comunidade e até mesmo envolvendo diferentes turmas ou instituições. ${ }^{3}$

É importante que o professor desenvolva competência para dirigir grupos de trabalho, para formar e renovar equipes pedagógicas, para enfrentar e analisar situações complexas e sinta-se preparado para administrar crises e conflitos interpessoais. ${ }^{7}$ Trabalhar em equipe é uma competência necessária tanto na formação em enfermagem, no contexto pedagógico, quanto na função de enfermeiro. ${ }^{9}$

Sob a ótica profissional, por exemplo, as vivências em equipe podem ser entendidas como parte estressante das atividades do enfermeiro, porém de reconhecida importância, necessitando, por isso, de profunda compreensão sobre seus fundamentos já no período acadêmico. ${ }^{13-14}$

\section{Participar da administração institucional}

Indiretamente, tudo que se faz na escola é gerir espaços e experiências de formação e ao professor cabe também esta tarefa. ${ }^{7}$ Interessar-se pelo que ocorre fora da sala de aula e com a comunidade educativa em seu conjunto, requer do docente participação na elaboração e na negociação do projeto institucional; na administração dos recursos disponíveis; na coordenação de ações sinérgicas; e na organização e evolução da participação dos alunos nesses contextos. ${ }^{3}$

\section{Informar e envolver a rede de apoio}

A rede de apoio é formada pela comunidade, família, pela gestão em educação, pelos serviços de saúde e por equipes de professores que reflitam sobre suas ações e constitui-se em uma rede de troca de conhecimentos, que permite, inclusive, descentralizar atividades da sala de aula. A atividade docente precisa estar comprometida com o ensino e a aprendizagem, mas, sobretudo, ancorada na responsabilidade social. ${ }^{15-16}$ Promover ações para a participação ativa dos alunos em atividades extramuros acarretam consequências educacionais profícuas. ${ }^{17}$ Cada sociedade se desenvolve, criando valores, normas, costumes, práticas e ideais que a regem, cimentando as relações em sociedades. ${ }^{17-18}$

\section{Utilizar novas tecnologias}

Com o advento da tecnologia e da globalização, é indispensável ao professor trazer novos meios de ensino para a sala de aula, utilizando aparatos tecnológicos. 0 ensino à 


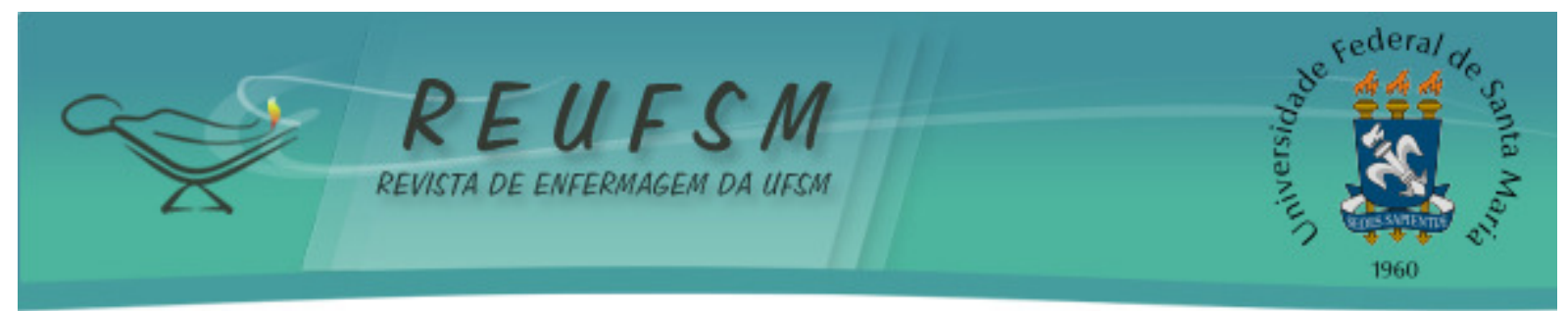

distância e a utilização de equipamentos tais como tablets ou celulares, possibilitam o acesso ao conhecimento de forma rápida e até mesmo síncrona em qualquer lugar do mundo.

O uso de tecnologias tais como editores de texto e equipamentos multimídia, pode enriquecer o aprendizado, favorecendo os meios de busca de conhecimento e retendo a atenção dos alunos. Não é apenas a ferramenta que é colocada em discussão, mas também a forma pedagógica que o professor utilizará para desenvolver as atividades. ${ }^{7,19}$

\section{Enfrentar os deveres e os dilemas éticos da profissão}

Os aspectos éticos destacados como competência docente envolvem a prevenção da violência em todos os espaços, a luta contra preconceitos de toda ordem, a participação na criação e significação de regras e valores de vida, de trabalho, de relações, o senso de responsabilidade, de solidariedade e de justiça. ${ }^{7}$

0 interesse ético tem tido foco na prática educativa como elemento que deve ser parte de todos os processos na sala de aula. ${ }^{20} \mathrm{O}$ dia a dia está repleto de situações que necessitam que o professor, por meio da mediação pedagógica, as transforme em situações de aprendizagem. ${ }^{21-22}$

\section{Administrar a própria formação contínua}

A formação contínua é responsável pelo desenvolvimento de todas as outras competências e promove a atualização de recursos cognitivos. ${ }^{3}$ Os espaços de ensino possuem contextos inéditos, que frequentemente se modificam, além disso possuem programas que são repensados em novas possíveis abordagens e paradigmas a serem compreendidos, o que exige a atualização constante do professor.

Administrar sua formação contínua é saber especificar suas próprias práticas e realizar um balanço de suas competências a fim de desenvolver um projeto de formação. ${ }^{7}$ Além disso, é relevante se envolver com atividades pertencentes a outras esferas, tais como as relacionadas às políticas profissionais e educacionais. ${ }^{7}$

\section{REFLEXÕES}

Embora as DCNs já tenham sido largamente discutidas e estarem em vigor desde o ano de 2001, é possível perceber que, analisando os pressupostos propostos por Perrenoud, o ensino na enfermagem permanece carente de atividades que fortaleçam práticas pedagógicas diferenciadas, principalmente, aquelas que situem a figura do aluno como sujeito ativo e central do processo de ensino. Isso perpassa pelo entendimento do professor de que a sua formação técnica e as competências necessárias enquanto docente são instrumentos a serem utilizados a favor de mudanças que favoreçam as discussões sobre o tema.

Há dificuldades em descentralizar o ensino da figura do professor, embora ideias sobre isso se façam verdadeiramente presentes e mostrem que uma possível renovação ou readequação do ensino não é um processo simples. Desta forma, pensar acerca das competências propostas por Perrenoud, suscita mudanças epistemológicas. Estes pressupostos são particularmente necessários aos professores de enfermagem, pois estes, geralmente, não possuem formação pedagógica e atuam na docência em função do domínio do conteúdo em determinada especialidade. ${ }^{23}$

Ao propor, organizar e dirigir situações de aprendizagem o professor aproxima-se de uma ciência da educação, bem como da compreensão deste universo distinto daquele da especialidade. Neste contexto, a percepção de que há a necessidade de lidar com 


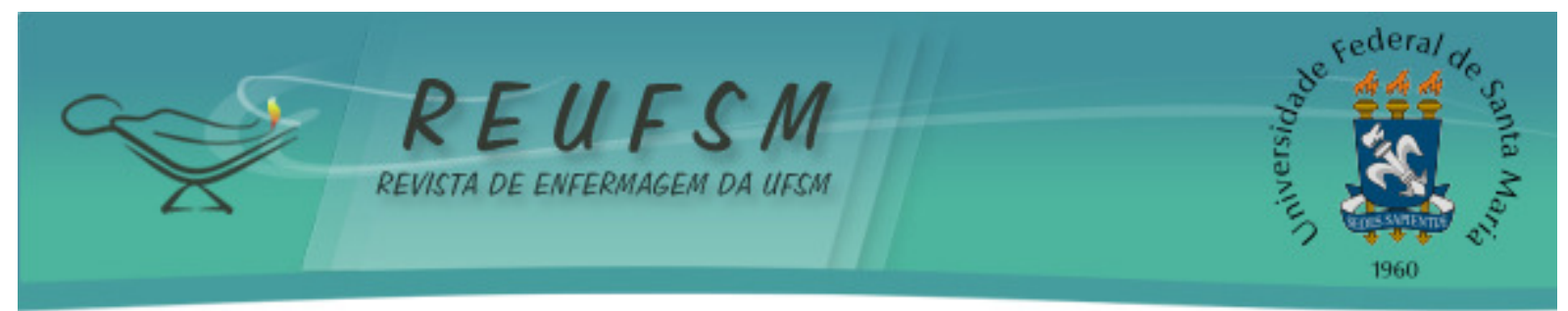

inteligências múltiplas e conceber o ensino como uma atividade que depende essencialmente dos sujeitos envolvidos, favorece o trabalho em equipe e fortalece as situações de aprendizagem.

Os conhecimentos sobre currículo, atividades de coordenação, gerenciamento das políticas educacionais e uso de tecnologia são partes importantes das atividades dos professores e devem ser incorporadas a complexidade do seu "fazer docente". Da mesma forma, fortalecer o pensamento crítico sobre a profissão e sobre os dilemas éticos dela advindos permitem ofertar ao aluno amplo entendimento sobre o mercado de trabalho, sobre as vivências dos enfermeiros e sobre as situações que constroem, fortalecem ou dificultam o contexto do trabalho na enfermagem.

Por certo que as competências propostas por Perrenoud não se constituem num caminho único para a compreensão das atividades do professor e seu papel no ensino na enfermagem. No entanto, a discussão advinda da leitura e compreensão destas competências endossa inúmeras reflexões sobre as práticas pedagógicas, as relações com alunos e universidades, e a formação de novos profissionais em seu complexo e amplo contexto. ${ }^{16}$

Para além de pensar novas práticas, há a necessidade de novas propostas que qualifiquem a ação docente. 0 entendimento da docência como uma atividade que requer preparo pedagógico associado ao domínio do conteúdo, fortalece o ensino na enfermagem e corrobora com a qualificação dos profissionais que atuarão na assistência. ${ }^{23}$

\section{CONSIDERAÇÕES FINAIS}

Em tempos em que se busca a qualidade no ensino superior no Brasil, o compromisso dos atores envolvidos, em geral, é buscar alternativas que possam compor um arcabouço de ideias, elementos, inovações criativas, informações e que possibilitem qualificar a profissão docente por meio da construção de competências.

Diante da reflexão realizada, percebe-se que as competências propostas por Perrenoud se complementam e não se encerram em si mesmas, formam um leque de possibilidades e orientações que permitem fomentar a consciência docente e podem ser adequadas para cada situação ou espaço.

Neste sentido, para se tornar um ser enfermeiro docente competente, é necessário se envolver com o âmbito educacional de forma ampla. É relevante considerar e relacionar as diversas mudanças que ocorrem tanto na prática docente quanto na enfermagem. Como mostra Perrenoud, o desafio é que os professores se percebam como organizadores de situações de ensino-aprendizagem e que envolvam seus alunos, desenvolvendo em si as múltiplas competências necessárias ao ofício de ser professor.

\section{REFERÊNCIAS}

1. Dolz J, Olllagnier E. O enigma das competências em educação. Porto Alegre: Artmed; 2004.

2. Pinhel I, Kurcgant P. Reflexões sobre competência docente no ensino de enfermagem. Rev Esc Enferm USP. 2007;41(4):711-16.

3. Perrenoud P. Dez novas competências para ensinar. Porto Alegre: Artmed; 2000.

4. Niemeyer F, Silva KS, Kruse MHL. Diretrizes curriculares de enfermagem: governando corpos de enfermeiras. Texto \& Contexto Enferm. 2010;19(4):767-73.

5. Ricardo EC. Discussão acerca do ensino por competências: problemas e alternativas. Cad Pesqui. 2010;40(140):605-28. 


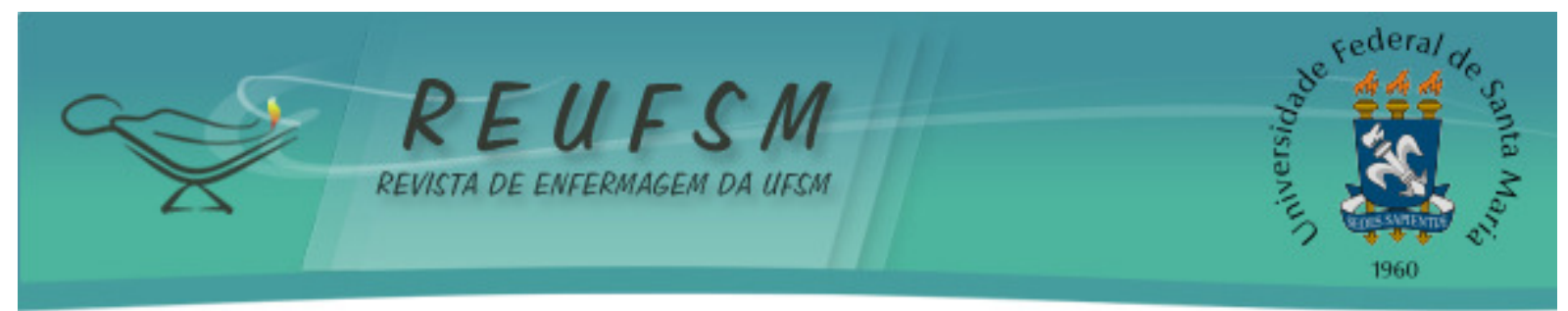

6. Freire P. Pedagogia da autonomia: saberes necessários à prática educativa. $43^{\mathrm{a}}$ ed. São Paulo: Paz e Terra; 2011.

7. Perrenoud P. Construir as competências desde a escola. Porto Alegre: Artes Médicas Sul; 1999.

8. Delors J. Educação: um tesouro a descobrir. $4^{\mathrm{a}}$ ed. São Paulo: Cortez; 2000.

9. Lima MM, Reibnitz KS, Kloh D, Wosny AM. Concepções de estudantes de enfermagem sobre a integralidade do cuidado à saúde. Ciênc Cuid Saúde. 2012;11(2):259-66.

10. Baccaro TA, Shinyashiki GT. Consistência da escolha vocacional e socialização profissional de estudantes de enfermagem. Rev Bras Orientac Prof. 2011;12(1):73-82.

11. Pereira WR, Ribeiro MRR, Depes VBS, Santos NC. Competências emocionais no processo de ensinar e aprender em enfermagem na perspectiva das neurociências. Rev Latinoam Enferm [Internet]. 2013 [acesso em 2014 jan 19];21(3):[07 telas]. Disponível em: http://www.scielo.br/pdf/rlae/v21n3/pt_0104-1169-rlae-21-03-0663.pdf.

12. Candau VM. Direitos humanos, educação e interculturalidade: as tensões entre igualdade e diferença. Rev Bras Educ. 2008;13(37):45-57.

13. Monteiro SC, Almeida LS, Vasconcelos RMCF. Abordagens à aprendizagem, autorregulação e motivação: convergência no desempenho acadêmico excelente. Rev Bras Orientac Prof. 2012;13(2):153-62.

14. Souza NVDO, Correia LM, Cunha LS, Eccard J, Patrício RA, Antunes TCS. 0 egresso de enfermagem da FENF/UERJ no mundo do trabalho. Rev Esc Enferm USP. 2011;45(1):250-7.

15. Silva VLS, Chiquito NC, Andrade RAPO, Brito MFP, Camelo SHH. Fatores de estresse no último ano do curso de graduação em enfermagem: percepção dos estudantes. Rev Enferm UERJ. 2011;19(1):121-6.

16. Silva LAA, Arboit EL, Muller LA, Prestes M, Dalmolin IS, Sassi MM. Percepções de professores enfermeiros sobre a intersecção do trabalho assistencial e docente. Rev Enferm UFSM [Internet]. 2014 abr-jun [acesso em 2015 abr 27];4(2):313-22. Disponível em: http://cascavel.ufsm.br/revistas/ojs-2.2.2/index.php/reufsm/article/view/10081/pdf.

Doi: $10.5902 / 2179769210081$.

16. Wolf-Wendel L, Ward K, Kinzie J. A tangled web of terms: the overlap and unique contribution of involvement, engagement, and integration to understanding college student success. J Coll Stud Dev. 2009;50:407-28.

17. Valle L. Ainda sobre a formação do cidadão: é possível ensinar a ética? Educ Soc. 2001;22(76):175-96.

18. Ceccim RB. Educação Permanente em Saúde: descentralização e disseminação de capacidade pedagógica na saúde. Ciênc Saúde Coletiva. 2005;10(4):975-86.

19. Moran JM. Ensino e Aprendizagem inovadores com tecnologias auditivas e temáticas. In: Moran JM, Masetto MT, Behrens M. As novas tecnologias e mediação pedagógica. $1^{\text {a }}$ ed. São Paulo: Papirus; 2000.

20. Koerich MS, Erdmann AL, Rosa VL. A formação ética: desafiando a prática educativa. Bioethikos. 2010;4(4):395-401.

21. Antunes C. Como desenvolver competências em sala de aula. $4^{\mathrm{a}}$ ed. Petrópolis: Vozes; 2001. 


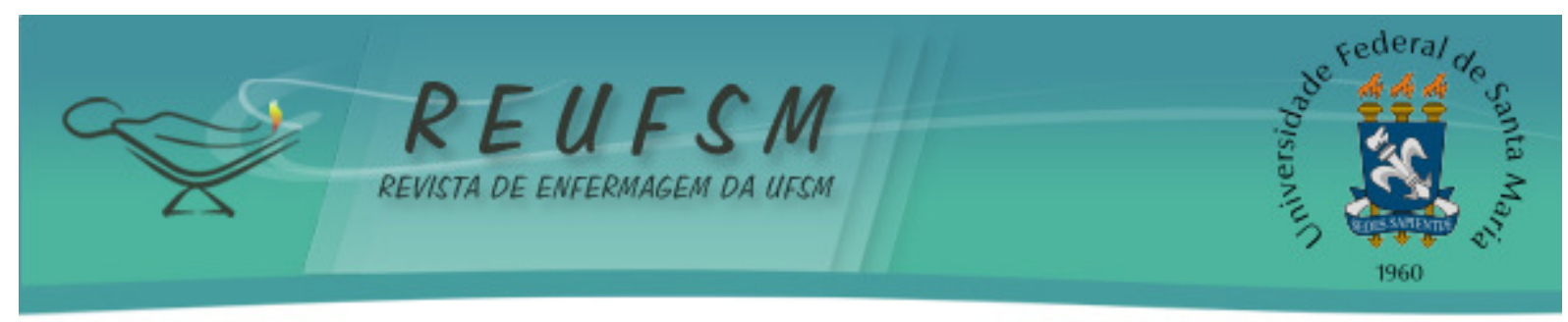

22. Guareschi APDF, Kurcgant P. Influência da formação docente no perfil do egresso de graduação em enfermagem. Cogitare Enferm. 2014;19(1):101-8.

23. Backes VMS, Moya JLM, Prado ML, Menegaz JC, Cunha AP, Francisco BS. Expressões do conhecimento didático do conteúdo de um professor experimentado de enfermagem. Texto \& Contexto Enferm. 2013; 22(3):804-10.

Data de recebimento: $24 / 06 / 2014$

Data de aceite: 29/04/2015

Contato do autor responsável: Daniele Delacanal Lazzari

Endereço postal: Universidade Federal de Santa Catarina, Centro de Ciências da Saúde. Departamento de Enfermagem. Bloco $\mathrm{H}, 4^{\circ}$ andar, sala 414. CEP 88040-900. Florianópolis, Santa Catarina, Brasil.

E-mail: danielelazza@gmail.com 